\section{Welcome back to your academic home: AMSSM special issue}

\author{
Christina L Master (ㄷ, ${ }^{1}$ Brett G Toresdahl (1) ${ }^{2}$
}

As with many life events marked in relation to March 2020 when COVID-19 became a global pandemic, the publication of this year's American Medical Society for Sports Medicine (AMSSM) special issue of the British Journal of Sports Medicine corresponds with the 2-year mark of this pandemic. During that time, AMSSM members (similar to our colleagues around the world) have learnt to navigate the ever-changing challenges of practising medicine, caring for sports teams, conducting research, advocating for healthy communities, and educating the next generation of sports and exercise medicine physicians during a pandemic. Without the AMSSM Annual Meeting in person the past 2 years, the membership of AMSSM has found new ways to engage and collaborate, such as through the National Fellow Online Lecture Series, Sports Ultrasound Case Presentations, Medical Student Interest Group Webinars and the 2021 virtual Annual Meeting.

In this context, we are proud to share with you the latest research and perspectives that capture important advances in sports and exercise medicine, contributed by both our AMSSM and international colleagues. Several topics highlighted in this issue will also be covered at the upcoming AMSSM thirty-first Annual Meeting, 8-13 April in Austin, Texas . These include concussion, sports cardiology, mental health, musculoskeletal ultrasound, transgender athletes, regenerative medicine and, of course, COVID19. Read this special issue and take this opportunity to whet your appetite for a great return to our in-person AMSSM Annual Meeting!

- Concussion

- Read an important study examining the diagnostic utility of common sideline concussion assessments, some new and some old, and determine for yourself

\footnotetext{
'Sports Medicine and Performance Center, Children's Hospital of Philadelphia, Philadelphia, Pennsylvania, USA

${ }^{2}$ Sports Medicine Institute, Hospital for Special Surgery, New York, New York, USA

Correspondence to Dr Christina L Master, Sports Medicine and Performance Center, Children's Hospital of Philadelphia, Philadelphia, PA 19104, USA; masterc@chop.edu
}

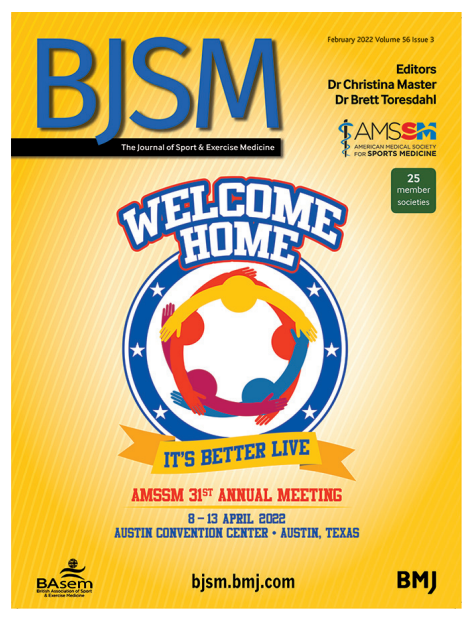

what is the best use of your time and effort in the evaluation of concussion. (see page 144)

Sports cardiology

- Review survival rates and find out which socioeconomic factors influence outcomes from exercise-related sudden cardiac arrest in high school athletes in the USA. (see page 138)

- Explore the novel association between race and maladaptive concentric left ventricular hypertrophy in American-style football athletes. (see page 151)

- Hear the heart-warming story of how Dr Joseph Marek and his team make a difference for young athletes through Young Hearts for Life with over a quarter-million cardiac screening tests completed and counting. (see page 173)

- Mental health

- Recognise the important intersection of sports, mental health and the media, and learn how you can more effectively advocate for your athletes. (see page 123)

- Embrace an important call to action to recognise and prevent vicarious and secondary traumatic stress in sport from athlete abuse. (see page 119)

- Familiarise yourself with the AMSSM Sports Ultrasound Curriculum for Sports Medicine Fellowships to be the most up-to-date on this important
- Musculoskeletal ultrasound facet of training and clinical practice. (see page 127)

- Transgender

- Learn how you can be a better ally and promote the health and wellbeing of your transgender athletes. (see page 125)

- Regenerative medicine

- Build your evidence base for the responsible use of regenerative medicine and orthobiologics in sports medicine with highlights from the AMSSM Position Statement. (see page 121)

COVID-19

- Be reassured that the risk of SARSCoV-2 transmission from on-field player contacts in football (soccer) is very low. (see page 158)

The theme of this year's AMSSM Annual Meeting is 'Welcome Home', which reminds us how fortunate we are to have academic homes within AMSSM and British Journal of Sports Medicine. It is within these academic homes that we can help one another address the many new challenges of the past 2 years, as well as learn new (and better) ways to address old challenges moving forward. We hope that the articles in this issue contribute to positive change in this 'new normal' and the world around you. We hope to see you in Austin, Texas at the AMSSM Annual Meeting!

Twitter Christina L Master @drtinamaster and Brett G Toresdahl @bretttoresdahl

Contributors CLM and BGT coauthored this piece.

Funding The authors have not declared a specific grant for this research from any funding agency in the public, commercial or not-for-profit sectors.

Competing interests None declared.

Patient consent for publication Not applicable.

Ethics approval This study does not involve human participants.

Provenance and peer review Commissioned; internally peer reviewed.

(C) Author(s) (or their employer(s)) 2022. No commercial re-use. See rights and permissions. Published by BMJ.

\section{(D) Check for updates}

To cite Master CL, Toresdahl BG. Br J Sports Med 2022;56:117.

Accepted 16 December 2021

Br J Sports Med 2022;56:117.

doi:10.1136/bjsports-2021-105355

\section{ORCID iDs}

Christina L Master http://orcid.org/0000-0002-67174270

Brett G Toresdahl http://orcid.org/0000-0003-38572779 